WPS3823

\title{
Nonlinear Effects of Altitude on Child Growth in Peru - A Multilevel Analysis
}

\author{
Alessandra Marini \\ amarini@worldbank.org \\ Michele Gragnolati \\ mgragnolati@worldbank.org
}

\begin{abstract}
Growth at high altitude has been the object of many investigations after experimental studies on animals showed that hypoxia at high altitude slows growth. Many studies have also looked at the Andean populations and found different results. Even though a few studies find that individuals living at high altitudes are smaller than the ones living at low altitudes, a significant group of studies does not reveal such a clear relationship. This study focuses on Peru, a country characterized by a diverse territory, great altitude variations and a population with a wide socioeconomic gradient. The present analysis differs from previous studies in three ways. First, in an attempt to reconcile the main findings of the biological literature with the economic models of child health, it explores the relationship between altitude and child health within a multivariate framework. Second, it benefits from a large spectrum of altitude data and does not concentrate on one or two isolated villages. Third, it takes into account the cluster nature of the data and controls for correlation of variables in the same cluster through multilevel statistical modeling. After controlling for characteristics of the children, families and communities, the data show a significant nonlinear relationship between altitude and child nutritional status. Peruvian children living at medium/high altitudes appear to be worse off than children living at extremely high altitudes, where the negative effect of hypoxia on growth could be compensated by other favorable health and environmental conditions.
\end{abstract}

World Bank Policy Research Working Paper 3823, January 2006

The Policy Research Working Paper Series disseminates the findings of work in progress to encourage the exchange of ideas about development issues. An objective of the series is to get the findings out quickly, even if the presentations are less than fully polished. The papers carry the names of the authors and should be cited accordingly. The findings, interpretations, and conclusions expressed in this paper are entirely those of the authors. They do not necessarily represent the view of the World Bank, its Executive Directors, or the countries they represent. Policy Research Working Papers are available online at http://econ.worldbank.org.

Acknowledgements: we are grateful for helpful suggestions and comments on an earlier version of this paper from Chris Barrett and Harold Alderman. 


\section{INTRODUCTION: MOTIVATION AND OBJECTIVES OF THE PAPER}

\subsection{Altitude and growth}

Growth at high altitude has been the object of many investigations after experimental studies on animals showed that hypoxia at high altitude slows growth (Gordon et al., 1943 and Moore and Price, 1948).

Previous studies looked at the effects of altitude on human growth exclusively from biological or physical anthropological perspectives. Studies on human growth proved that altitude influences anthropometric outcomes but did not show uniform and uncontroversial results on the influence of altitude on height. Pawson (1977) does not find a significant difference between the high altitude Sherpa and the low altitude Tibetan (living in Nepal). Malik and Singh (1978) find that in India children living at high altitude are taller than low altitude children in late adolescence but the opposite is true for children in early adolescence. Clegg et al (1972) show that in Ethiopia children living at high altitude are taller than children living at low altitude, maybe because of the higher prevalence of infectious diseases (such as malaria) at low altitude. Many studies have also looked at the Andean populations and found different results. Even though a few studies showed that individuals living at high altitudes were smaller than the ones living at low altitude (Haas, 1976; Frisancho and Baker, 1970; Beall et al., 1977, Mueller et al., 1978), a significant group of studies could not reveal such a clear relationship (Hoff, 1974; Pawson, 1977, Clegg et al. 1972, Frisancho et al, 1975). In general, consensus seems to exist only with regard to the increased chest size of high altitude populations.

There are many ways through which altitude can have an effect on child health. Higher altitude is often associated with more difficult transportation, which, on one side, can lead to higher food prices and have an impact on the diet of the children and, on the other side, to more difficult access to health facilities. Moreover higher altitude can be associated with worse crop outcomes and have an impact on the diet of the population and on their available resources. Unfortunately we were unable to find data on prices, transportation or crops for our study. We are therefore unable to disentangle the different mechanisms through which altitude can affect child health but notwithstanding we can say something about their relationship at the national level. Understanding the role of altitude can shed some light on the effect of other factors on anthropometric outcomes. Indigenous population is often found at disadvantage even after controlling for income and infrastructure. That could be due to unobservable factors such as social exclusion or to the correlation of ethnicity and altitude (Alderman et al, 2000). Being able to control for altitude allows disentangling the two separate effects.

The majority of studies looking at the health effects of altitude belong to the biological literature and, as a typical research strategy, used to contrast native populations at different altitudes (Baker, 1978). Those studies were therefore able to take into account ethnic background (and genetic variations for adolescents and adults) but often looked at the growth profile of a person as result of a single environmental factor in isolation rather then viewing it as the result of different factors and their interaction. In particular, those studies could not control for other environmental factors such as disease prevalence, 
nutritional intake and maternal care that have been proved to contribute to large differentials in child health (Mosley and Chen, 1984). Many of these factors would be endogenous in a classical study of determinants of health but could be accounted for by controlling for household income, household resources, parents' education and availability of infrastructure.

The study focuses on Peru, a country characterized by a very diverse territory and great altitude variations. The central portion of Peru includes the great mountain and plateau region of the Andes, with numerous peaks rising to over 6,000 meters and with extensive plateau districts between 3,000 meters and 4,300 meters. There is a very narrow coastal plain on the Pacific shore, while to the east of the Andes, the land drops steeply to the forested lowlands of the Amazon basin.

In what follows we look at the relationship between child growth and altitude within a classical Beckerian model of the family. The present analysis differs from previous studies in three ways. First, in an attempt to reconcile the main findings of the biological literature with the economic models of child health, we explore the relationship between altitude and child health within a multivariate framework. Second, we benefit from a large spectrum of altitude data and do not concentrate on one or two isolated villages. The majority of altitude studies on Peru, for example, used a sample of individuals from the rural highland community of Nuñoa (4000 mt). Later studies (Leonard et al. 1990) showed that Nuñoan are among the smallest of all Andean population and it would therefore be misleading to use them as evidence of the negative effect of altitude. It has been shown that a combination of both ecological and sociological constraints on food availability puts people in Nuñoa under nutritional stress as much as it does for other population in developing countries around the world. Finally, and more importantly, our analysis takes into account the cluster nature of the data and control for correlation of variables in the same cluster through a multilevel analysis.

\subsection{Hierarchically Clustered Data}

The data we are using for the analysis of child health in Peru present a hierarchical structure: factors affecting health outcomes arise from different levels of aggregation: the outcome of interest, child health, takes place at the individual level and is influenced by higher level characteristics which do not vary between individuals of the same group (household and community). In general household level or community level factors are of great interest because they can often be influenced by policies to affect individual level variables. In previous studies, higher level determinants of child health have always been observed and included in the analysis. The inclusion of multilevel factors among the determinants does not change the interpretation of the effects of those factors. Problems may arise if higher levels unobserved characteristics influence the lower level variables. The OLS estimator is as efficient as the maximum likelihood estimator only when the community level covariates and the household level covariates are uncorrelated with all the individual covariates (Angeles, Guilkey and Mroz, 2002). In general, however, the OLS estimator understates the true standard errors. 
Researchers have often adopted fixed effects models to estimate nutrition models and control for unobservable variables at the cluster level. The main difficulty in using fixedeffect models is that if the fixed effect is differenced away, then the effect of those variables that do not vary within a cluster will be lost in the estimation process. And that is particularly problematic in our analysis of the relationship between altitude and growth since altitude data are available only at the cluster level. We use a multilevel analysis model because of the clustered nature of the data and because we want to incorporate context in our analysis in order to study the impact of altitude.

\section{MODEL AND EMPIRICAL STRATEGY}

\subsection{Beckerian model of the household}

The analysis that follows is based on a standard Beckerian model of the household. Households are assumed to maximize a utility function defined over consumption of a composite good (the vector of consumption goods of different individuals in the household), household members' leisure and their health. Households maximize their utility function under several constraints, including a time constraint, a budget constraint, and a biological health production function. The health production function relates the health status of the child to his or her past health conditions and a set of inputs chosen by the household (including food intake, breastfeeding, utilization of health facilities, and the time dedicated by the mother to health related activities), a set of exogenous characteristics (such as the child's age and gender), a set of household characteristics including parents' health and education, their investment in child care, household resources and the available facilities.

The family optimization problem can be solved to yield a reduced-form equation for health outcomes in which child health depends only on exogenous individual, household, and community characteristics:

$$
\mathrm{N}_{\mathrm{i}}=\mathrm{n}\left(\mathrm{C}_{\mathrm{i}}, \mathrm{C}_{\mathrm{h}}, \mathrm{C}_{\mathrm{c}}, \varepsilon_{\mathrm{i}}\right) \text {, }
$$

where: $\mathrm{N}_{\mathrm{i}}$ is the height-for-age $\mathrm{z}$-score for child $\mathrm{i} ; \mathrm{C}_{\mathrm{i}}$ are the individual characteristics of the child, including age and sex; $\mathrm{C}_{\mathrm{h}}$ are household characteristics that incorporate measures of family background, including resource availability, parents' health, and parents' skills, measured generally by their level of education, and whether the father is absent from the household; $\mathrm{C}_{\mathrm{c}}$ are community characteristics, including altitude level, the availability of health services, the state of infrastructure such as water and sewage, and other community characteristics that affect child health through the proximate determinants; and $\varepsilon_{\mathrm{i}}$ is an individual specific random disturbance associated with the anthropometric outcome of the child and assumed to be uncorrelated with the $\mathrm{C}$ variables.

Estimation of the reduced-form anthropometric function does not provide information on the biological mechanisms responsible for children's growth deficits, but it does provide a consistent statistical framework within which to estimate the impact on children's health and nutrition of individual, household and community exogenous variables that are generally open to policy intervention. The parameter estimates of the coefficients in the 
reduced-form equation can be interpreted as the full effects of exogenous covariates, that is their effects not mediated by the proximate determinants.

\subsection{Multilevel Analysis}

Traditionally reduced form models are estimated with ordinary least square techniques. One of the critical assumptions of OLS models is the independence of disturbance. But in cluster samples, such as our data, observations are not independent: the growth experience of children within the same community may be similar, especially if they come from the same family. OLS estimates of this type of data can therefore result in inefficient estimates of the parameters and underestimated standard errors. By ignoring the hierarchical structure of the data we are ignoring a significant and interesting community effect. As evident in the graph below, that represents the average z-score by community, the average $\mathrm{z}$-score varies substantially across communities (figure 1).

Figure 1 - Cluster mean of HAZ against cluster

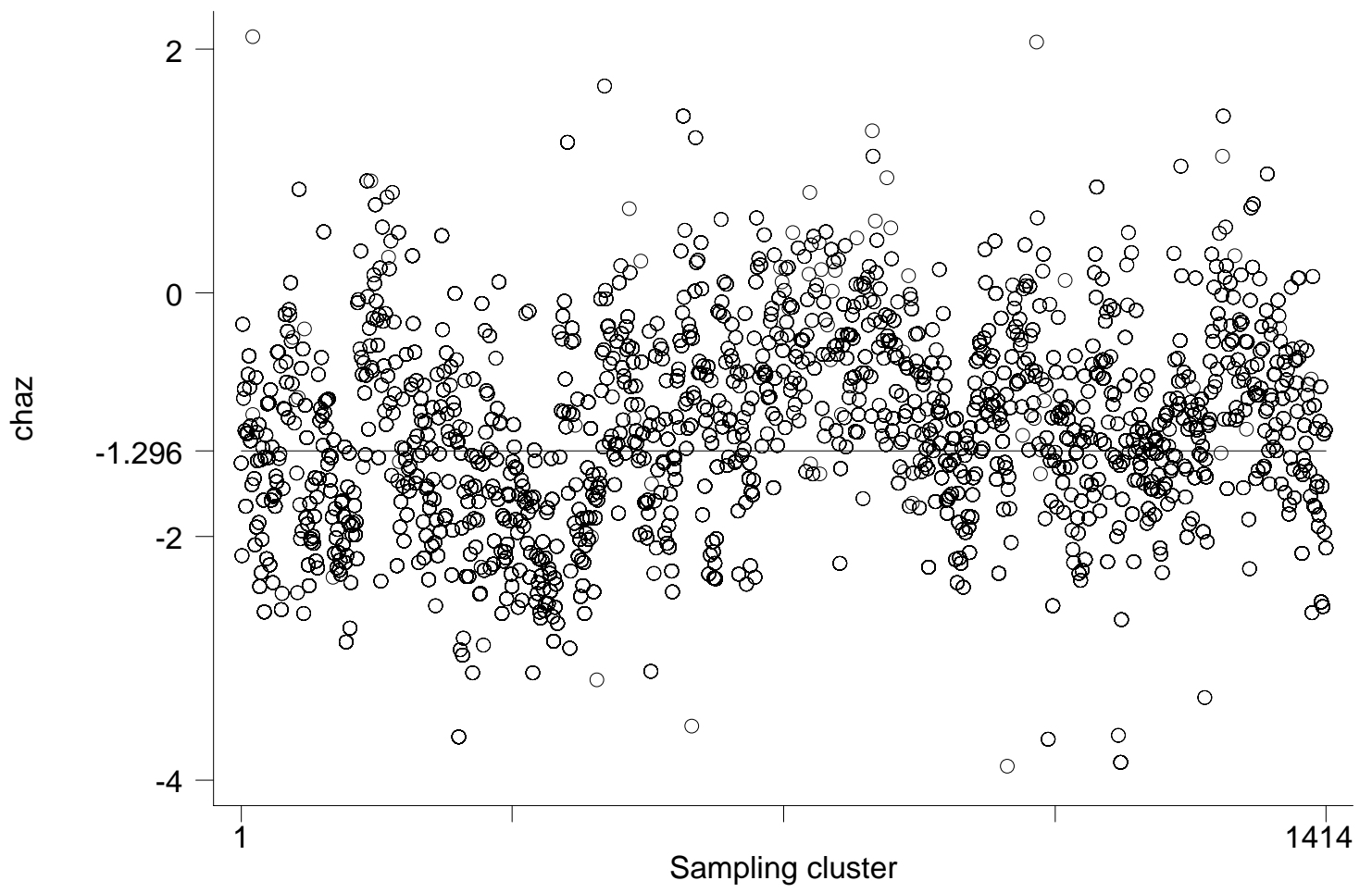

Source: Author's calculation using Peru DHS 2000 data.

Multilevel models are random effect models, which take into account the hierarchical nature of the data. Individuals but also households and communities are the unit of analysis. (Kreft, de Leew, 1994). In these models the greater homogeneity of observations in the same group is modeled by adding a random effect at each cluster:

$$
\mathrm{z}_{i j k}=\beta^{\prime} \mathrm{x}_{\mathrm{ijk}}+\delta_{k}+\mu_{j k}+\varepsilon_{i j k}
$$


where $z_{i j k}$ is the height-for-age $z$-score for the ith child of the $j$ th family in the $k$ th community; $\beta$ is a vector of regression coefficients corresponding to the effects of fixed covariates $\mathrm{x}_{\mathrm{ijk}}$, which represent observed characteristics of the child, the family and the community; $\delta_{k}$ is a random community effect that represents the deviation of community $k$ 's mean z-score from the grand mean; $\mu_{\mathrm{jk}}$ is a random family effect that represents the deviation of family $j k$ 's mean z-score from the mean of community $k$; and $\varepsilon_{i j k}$ is an individual error term that represents the deviation of child ijk's z-score from the mean of family $j k$.

The random effects $\mu_{\mathrm{jk}}$ and $\delta_{k}$ represent unobserved family and community factors shared between siblings and between children living in the same community respectively. Anthropometric outcomes of children living in the same community (but not in the same family) are correlated because they share the random effect $\delta_{k}$, and anthropometric outcomes in the same family are correlated because they share the random effects $\delta_{k}$ and $\mu_{j k}$.

The error terms $\delta_{k}, \mu_{j k}$, and $\varepsilon_{i j k}$ are assumed to be normally distributed with mean zero and variances $\sigma_{c}^{2}, \sigma_{f}^{2}$, and $\sigma_{i}^{2}$ respectively. If $\sigma_{c}^{2}$ is zero, observations in the same community (but not in the same family) are independent. If $\sigma_{\mathrm{f}}^{2}$ is also zero, observations belonging to the same family are also independent. If $\sigma_{c}^{2}$ and $\sigma_{f}^{2}$ are not zero, the observations are correlated and the OLS assumption of independence does not hold. The variances of the random terms are the additional parameters estimated by variancecomponents models as compared to OLS linear regression models. To the extent that the greater homogeneity of within-cluster observations is not explained by the observed covariates, $\sigma_{c}^{2}$ and $\sigma_{f}^{2}$ will be larger. To evaluate the appropriateness of our model we therefore test whether the variances of the random part are different from zero over families and over communities.

In these models the coefficients can be fixed (variance component models) or random (random coefficient models) and the choice can be made separately for every coefficient. For example, we can think of the effect of household resources on child health as varying from community to community instead of being fixed across communities. This would be equivalent to assuming that the slope of asset index is also a random effect $\beta_{\mathrm{i}}$, which we assume normally distributed with mean $\beta$ and variance $\sigma^{2}{ }_{\beta}$, where $\beta$ is now the average effect of household resources across the surveyed communities.

As mentioned before, multilevel models don't assume that observations of different individuals in the same family or in the same community are independent. As a matter of fact, from the resulting estimates we are able to assess the extent to which child health is correlated within families and within communities, before and after we have taken into account the effect of the observed covariates $\mathrm{x}_{\mathrm{ijk}}$. The Intra Class Correlation (ICC) coefficient, in particular, is used to assess the amount of covariation between observations belonging to the same group. Zero correlation means that the observations are independent. ${ }^{1}$ When the correlation is different from zero, it is more appropriate to

\footnotetext{
${ }^{1}$ Because we are assuming that the errors are normally distributed.
} 
use random effect models. Note that even small values of ICC have been showed to lead to type I errors that are much larger than the normal alpha level of 0.05 (Hox and Kreft, 1994).

The ICC coefficient describes the proportion of variation that is attributable to the higher level source of variation. The correlations between the anthropometric outcomes of children in the same community and in the same family are respectively ${ }^{2}$ :

$$
\rho_{\mathrm{c}}=\sigma_{\mathrm{c}}^{2} /\left(\sigma_{\mathrm{c}}^{2}+\sigma_{\mathrm{f}}^{2}+\sigma_{\mathrm{i}}^{2}\right)
$$

and

$$
\rho_{\mathrm{f}}=\left(\sigma_{\mathrm{c}}^{2}+\sigma_{\mathrm{f}}^{2}\right) /\left(\sigma_{\mathrm{c}}^{2}+\sigma_{\mathrm{f}}^{2}+\sigma_{\mathrm{i}}^{2}\right)
$$

The total variability in individual anthropometric scores can be partitioned into its three components, that is variance among: children within families, families within communities, and communities. Multilevel models allow us to evaluate whether child health can be attributed to individual differences, differences between households or structural differences between communities. Finally, by including covariates measured at the individual-, household-, and community-level, variance-components models enable us to explore the extent to which community differences in average height-for-age zscores are accountable for by factors operating at each level.

\section{DATA}

The Peru Demographic and Health Survey of 2000 (DHS 2000) is a nationally representative, probabilistic, self-weighted, stratified survey that covers 28,900 households and 27,843 women between 15 and 49 years. Two questionnaires were covered in the survey. The household questionnaire collected information on the characteristics of the households like economic activity, assets and infrastructure and achieved education level. The individual questionnaire collected a series of information on women's background, their reproductive and fertility history, and their health, including anthropometric measurements of their children. Our investigation was restricted to 11,585 children between 0 and 60 month whose anthropometric measurements were available.

The data used in the study are characterized by a hierarchical structure: individuals are nested within households ${ }^{3}$ and households are nested within communities (clusters). The

\footnotetext{
${ }^{2}$ The intra family correlation coefficient takes into account the fact that children in the same families also live in the same communities.

${ }^{3}$ The DHS survey collected information for every mother in the family. In theory, we could have therefore set up a four level model with random effects at the individual, mother, household and community level. But the limited number of families with more than one mother (3\%) and the reduced size of the household level cluster did not make it possible. For those families with more than one mother we have collapsed mothers' information at the family level. To do so we kept the age of the oldest mother and the education level of the most educated mother, based on the assumption that experience and education of the woman in the family can have a positive externality effect on all the children in the family. We defined as nonindigenous those families where there was at least one non-indigenous mother, again based on the
} 
11,585 children of whom we have observations come from 8,925 families distributed around 1,325 clusters. Sample sizes averaged about 8 children per community, and 1 child per family. The fact that the clusters are very small (on average 6 families per community) justifies even more the adoption of multilevel models. Child health is measured by the height for-age z-score, an indicator of stunting. Stunting represents the accumulated consequences of retarded skeletal growth. It reflects the cumulative effects of the many different insults that children in developing countries experience in the uterine and preschool years and is frequently found to be associated with poor overall economic conditions. Moreover stunting is largely irreversible after 2 years of age and for this reason is considered an accurate indicator of long-term chronic malnutrition in early childhood (Keller, 1983; Behrman and Deolalikar, 1988; Strauss and Thomas, 1998, Martorell and Scrimshaw, 1995). The average height-for-age z-score of children in the sample is -1.17 for boys and -1.18 for girls. $25.2 \%$ of the boys and $25.6 \%$ of the girls in the sample are stunted.

\section{ALTITUDE AND MALNUTRITION: DEBUNKING AN OLD MYTH?}

Most of the empirical studies that analyzed the relationship between altitude and human growth compared anthropometric data of genetically similar populations living in two different villages or communities, one at high altitude (above 3500 or 4000 meters) and the other at low altitude (at sea level or below 1500 meters). The results of the different studies have been equivocal with respect to specific effects of hypoxia on growth. As suggested by Mueller et al. (1978), some of the lack of consistencies in the results of human studies could reflect the failure to keep constant other factors that vary with altitude, beside hypoxia. The purpose of the following analysis is to explore the relationship between growth and altitude from a different perspective, using a spectrum of altitude data that covers the whole country and estimating the relationship within a household demand framework that allows taking into account (directly and indirectly) the most important determinants of child health.

assumption of positive externalities coming from a Spanish-speaking person in the family (ethnicity is a language-based definition). 
Figure 2 - Average Height-for-Age Z-Scores by Altitude Level (1994, 1996, 1997, 2000)

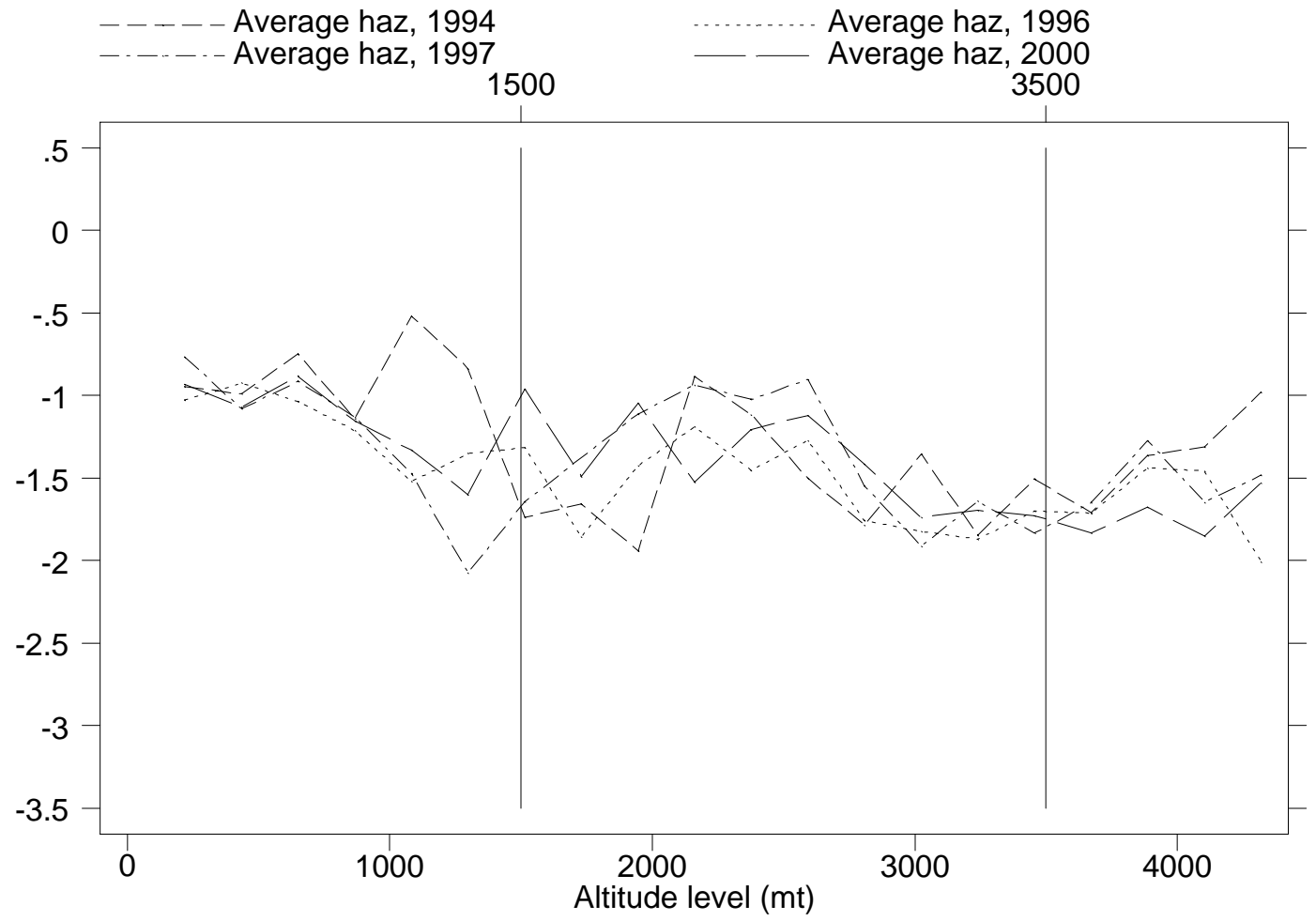

Source: Author's calculations using data from ENNIV94, ENNIV97, DHS96, DHSO0.

Figure 2 shows the average height-for-age z-score per altitude level in four different periods in time. The first striking observation is the great uniformity of the different trend lines: despite the differences in survey methodologies, samples and sample sizes, the relationships between altitude and malnutrition look very similar over time. One possible explanation is that factors affecting growth at different altitude levels were unchanged over the period 1994-2000.

The data also show the existence of a downward trend in height for age z-scores up to 3500 meters. According to the data, it seems that the smallest children live between 2500 and 3500 meters. Another notable and unusual outcome is the slight upward trend in children's growth above 3500 meters confirmed by all the surveys but DHS 1996 .

Note that if we sampled two separate groups of children, one from communities below 1500 meters, and the other from communities above 3500 meters, as biological studies did in the past, we would have quite likely observed that children living at higher altitudes were smaller than children living at lower altitudes. On the other side, when analyzing the variation in altitude and growth at the country level we find a more complex and non-linear relationship, as illustrated by table 1 below.

In an unconditional model, where height for age z-score is regressed simply on altitude levels without taking into account differences in other household or community characteristics, child growth worsens at different rates with increasing altitude levels. If 
we control for household resources then children living between 2500 and 3500 meters have worse health outcomes than children living above 3500 meters and this relationship is even stronger if we also control for family's background characteristics (as represented by mother's height).

Table 1 - Non-Linear Relationship Between Child Growth and Altitude

\begin{tabular}{lccc}
\hline & $(1)$ & $(2)$ & $\begin{array}{c}(3) \\
\text { asi \& mheight }\end{array}$ \\
\hline Constant & -0.86427 & -0.89423 & -9.48867 \\
& $(55.85)^{* * *}$ & $(61.33)^{* * *}$ & $(31.22)^{* * *}$ \\
altitude $>=1500,<2500 \mathrm{mt}$ & -0.46529 & -0.19425 & -0.21426 \\
& $(10.23)^{* * *}$ & $(4.48)^{* * *}$ & $(5.10)^{* * *}$ \\
altitude $>=2500,<3500 \mathrm{mt}$ & -0.79977 & -0.44405 & -0.43254 \\
& $(25.86)^{* * *}$ & $(14.55)^{* * *}$ & $(14.63)^{* * *}$ \\
altitude $>=3500 \mathrm{mt}$ & -0.83976 & -0.40654 & -0.38861 \\
& $(23.85)^{* * *}$ & $(11.62)^{* * *}$ & $(11.45)^{* * *}$ \\
Household asset index & & 0.50918 & 0.42207 \\
& & $(38.74)^{* * *}$ & $(32.21)^{* * *}$ \\
Mother's height $(\mathrm{cm})$ & & & 0.05702 \\
Observations & 11585 & 11585 & $(28.31)^{* * *}$ \\
R-squared & 0.08 & 0.19 & 11506 \\
\hline
\end{tabular}

Absolute value of $t$-statistics in parentheses

* significant at 10\%; ** significant at 5\%; *** significant at $1 \%$

Figure 3 and 4 below show growth patterns by age groups for four different altitude levels. Nutritional status of children living at higher altitude appears to be worse that that of children leaving at lower altitudes, but once again children living above 2500 meters are not necessarily worse off than children living between 1500 and 2500 meters.

Figure 3 -Female Stunting by altitude and age group

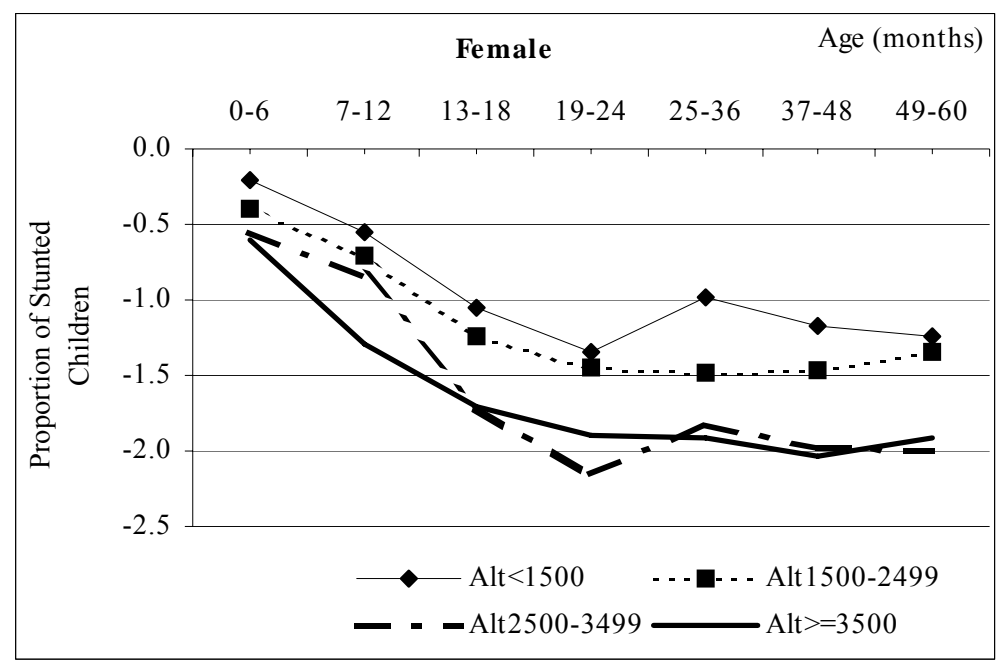

Source: Author's calculation using Peru DHS 2000 data. 
Figure 4 -Male Stunting by altitude and age group

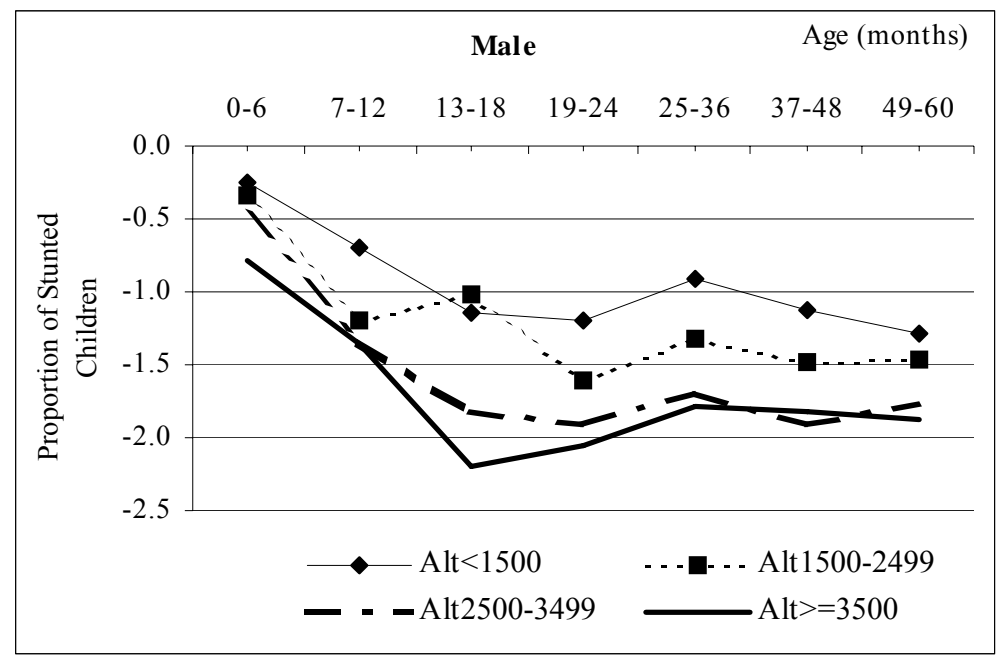

Source: Author's calculation using Peru DHS 2000 data.

This complex relationship between altitude and child growth could be the outcome of a combination of opposite forces operating at the same time. The negative effect of hypoxia on growth at high altitudes could for example be compensated by the existence of more difficult health conditions (such as higher prevalence of infections) or by worse environmental conditions (such as pollution in urban areas) at lower altitudes. Finally, an alternative explanation may come from variations in agricultural production at different altitude levels and specifically by the fact that above 3,500 meters Peruvian peasants tend to stop cultivating maize and secure land for pastoralism (Cotlear, 1986) with consequences on their diets that is likely to be much richer in protein.

\section{RESULTS}

In this section we analyze the relationship between child malnutrition and altitude in Peru controlling for the effect of different exogenous characteristics. We adopt a multilevel model to control for clustering and to be able to add context (altitude) in the analysis. ${ }^{4}$ Malnutrition will be explained by three groups of variables: individual, household and community -level variables. Means and standard deviations of these variables are presented in table 2 .

We have fitted several models in order to better understand the relationship between altitude and nutritional status. We start by fitting a reference model (model 1) that includes only age and gender of the child. Model two includes dummies for altitude ranges to represent the non-linear relationship between altitude and child growth. Model three is a full model that includes all the exogenous covariates and in model four we add the interaction between altitude and migration history of the mother.

\footnotetext{
${ }^{4}$ All the computations have been carried out using the MlnWin computer package (Rasbash et al., 2000).
} 
Table 2 - Means and Standard Deviations

\begin{tabular}{|c|c|c|c|c|c|}
\hline Variables & $\begin{array}{c}\text { Number of } \\
\text { Observations }\end{array}$ & Mean & $\begin{array}{c}\text { Standard } \\
\text { Deviation }\end{array}$ & Minimum & Maximum \\
\hline height for age $\mathrm{z}$-score & 11585 & -1.296 & 1.337 & -5.95 & 5.99 \\
\hline male dummy & 11585 & 0.503 & 0.500 & 0 & 1 \\
\hline age in months & 11585 & 30.414 & 17.134 & 0 & 59 \\
\hline mother's height & 11508 & 150.278 & 5.435 & 131.2 & 197.6 \\
\hline age of the mother - years & 11585 & 29.522 & 7.000 & 15 & 49 \\
\hline mother has completed primary education & 11585 & 0.439 & 0.496 & 0 & 1 \\
\hline mother has completed secondary education & 11585 & 0.335 & 0.472 & 0 & 1 \\
\hline mother has completed post-secondary education & 11585 & 0.138 & 0.345 & 0 & 1 \\
\hline mother is indigenous & 11585 & 0.214 & 0.410 & 0 & 1 \\
\hline father has completed primary education & 11585 & 0.348 & 0.476 & 0 & 1 \\
\hline father has completed secondary education & 11585 & 0.413 & 0.492 & 0 & 1 \\
\hline father has completed post-secondary education & 11585 & 0.164 & 0.370 & 0 & 1 \\
\hline asset index & 11585 & -0.418 & 0.885 & -1.672 & 1.307 \\
\hline Household size - number of people & 11585 & 6.190 & 2.366 & 2 & 19 \\
\hline number of children age $0-5$ & 11585 & 1.516 & 0.657 & 1 & 5 \\
\hline number of women age $16-25$ & 11585 & 0.567 & 0.710 & 0 & 8 \\
\hline number of women age $26-65$ & 11585 & 0.942 & 0.629 & 0 & 5 \\
\hline altitude - meters & 11585 & 1703.9 & 1551.7 & 3 & 4723 \\
\hline alt $0-1500$ & 11585 & 0.516 & 0.500 & 0 & 1 \\
\hline alt $1500-2500$ & 11585 & 0.085 & 0.279 & 0 & 1 \\
\hline alt $2500-3500$ & 11585 & 0.222 & 0.416 & 0 & 1 \\
\hline alt $>3500$ & 11585 & 0.176 & 0.381 & 0 & 1 \\
\hline urban area dummy & 11585 & 0.456 & 0.498 & 0 & 1 \\
\hline Proportion of hh with low qual floor & 11585 & 0.579 & 0.380 & 0 & 1 \\
\hline Proportion of hh with piped water & 11585 & 0.499 & 0.416 & 0 & 1 \\
\hline Proportion of hh with water from river/stream & 11585 & 0.303 & 0.365 & 0 & 1 \\
\hline Proportion of hh with flush toilet & 11585 & 0.275 & 0.372 & 0 & 1 \\
\hline Proportion of hh with no toilet & 11585 & 0.343 & 0.345 & 0 & 1 \\
\hline Proportion of hh with electricity & 11585 & 0.523 & 0.433 & 0 & 1 \\
\hline Proportion of hh with tv & 11585 & 0.539 & 0.391 & 0 & 1 \\
\hline Proportion of hh with fridge & 11585 & 0.190 & 0.281 & 0 & 1 \\
\hline Proportion of hh with phone & 11585 & 0.095 & 0.200 & 0 & 1 \\
\hline Migrated before child'd birth - dummy & 11585 & 0.493 & 0.500 & 0 & 1 \\
\hline
\end{tabular}

Source: Author's calculation using Peru DHS 2000 data.

\section{The parameter estimates are presented in table 3.}

Estimates of the reference model presented in column 1 are a useful preliminary step as they provide information about the outcome variability at each level..$^{5}$ A substantial part of the total variance $(42 \%)$ is attributable to family and community level variation in the height-for-age $\mathrm{z}$ scores. The individual variation is almost three-times higher than the variation at the community or family level. Part of this variation is due to measurement

\footnotetext{
${ }^{5}$ The estimation method is Iterative Generalized Least Squares (IGLS) and convergence is judged to have occurred when all parameters between two iteration have changed by less than a tolerance of $10^{-2}$.
} 
errors originating by either misreported height or age of the child. Interestingly, there is more variation between communities than between families, possibly reflecting the great geographical differences of the country. As a matter of fact, differences in altitude levels account for an important proportion of the variation between different communities: if we add altitude to the reference model (model 2) we immediately observe a significant reduction in the community variability (by $31 \%){ }^{6}$ In model 2 the effect of altitude on child growth is negative and significant. Without controlling for further exogenous characteristics, the model shows that child's nutritional outcome worsens monotonically as altitude increases.

As a next step we control for the relevant factors at the individual, household and community level (model 3, 4 and 5). Note that the individual random effect remains very high even after including other covariates as the only individual level variables used in the analysis are age and sex. On the other side, estimates of family variation indicate that a good part of it (approximately 30\%) is explained by the observed exogenous factors in the model while $86 \%$ of community variation is explained. ${ }^{7}$

The effect of altitude is highly significant in all model specifications. Note that after controlling for the individual, household and community characteristics, the relationship between altitude and child nutritional status becomes non-linear. Peruvian children living at medium/high altitudes (between 2500 and 3500 meters) appear to be worse off than children living at extremely high altitudes (above 3500 meters). These results should be interpreted with some caution as the altitude variables could be capturing other geographical and environmental characteristics not included in our model. Unfortunately, we were unable to find data on prices, soil characteristics, transportation: variables that are often correlated with altitude and may have helped disentangling the different mechanisms through which altitude affects child health. The large proportion of community level variance explained by the model (85\%) suggests on the other side that most of the variables explaining differences between various communities have been included.

In model 4 we control for the migration history of the family and test whether the fact that the mother had been living at high altitudes before the child's birth had an impact on the nutritional status of the child. We expect that, if there is an hypoxia effect, longer exposure to high altitudes would have a negative effect on nutritional outcomes. To do

\footnotetext{
${ }^{6}$ We formally test that adding altitude dummies improves the fit of the model by using a likelihood ratio test. The difference between $-2 \mathrm{LL}$ for the reference model and the model with altitude dummies can be compared to the $\chi^{2}$ distribution on 3 degrees of freedom (we are including three extra parameters). The difference is 307 . This value is highly significant (P-value: 0.000 )

${ }^{7}$ Note that in a multilevel model such as the one above, the inclusion of an extra explanatory variable with a fixed coefficient will generally change either (or all) the level 1, level 2 and level 3 variances. If, for example, the variable is measured at level 2 then the general effect will be to reduce the level 2 variance but leave the level 1 variance unaffected. When the variable is uncorrelated with the level 2 residuals we would not expect any reduction in the level 2 variance. If instead the variable is measured at level 1 then the level 1 variance will generally be reduced. If is a cross-level interaction term then both variances can increase (because it practically becomes a level 1 variable). If $\mathrm{x}$ is measured at level 1 , however, then the level 2 variance can increase since the level 2 residuals are now conditioned on a further variable.
} 
so, we interact altitude dummies with a dummy that is equal to one if the mother moved to the actual location before the birth of the child. We find that the only significant interaction is that between the migration dummy and the dummy for living between 1500 and 2500 meters. It would seem that altitude affects nutritional status of the child independently of the duration of the exposure, perhaps because of other effects that altitude may capture. The migration dummy taken by itself ("mother moved to the village before the child's birth") is on the other side significant and positive in all models, indicating that children whose mothers have been living in the current village before giving birth are better off than children whose parents moved only recently and possibly that hypoxia is not the driving mechanism. The result suggests that the process of adjustment and adaptation to a new community and its social life can have a negative effect on the nutritional outcome of the child.

In model 5 we control for the health characteristics of the regions that children live in by including the regional infant mortality rate. We do that for two main reasons. First, we are trying to indirectly capture the health characteristics of the area, including availability and quality of health services. Second, we are worried about a potential selection bias: that the children we observe at high altitudes are those who survive the difficult health and environmental conditions and therefore the healthiest ones. Controlling for mortality slightly affects the estimates of the altitude coefficients but does not change the main results. Living at medium-low altitudes (1500-2500 meters) is no longer significantly different from living at very low altitudes. Moreover, as consistent with previous estimates, children living at very high altitudes are better off than children living at medium-high altitudes. ${ }^{8}$

The other results of the model are consistent with the standard literature of economic determinants of malnutrition. Unsurprisingly for Latin America, there is no evidence of gender differences in child growth. Also, results confirm the cumulative nature of stunting, which increases monotonically especially during the first two years of the child (weaning age) and then tends to stabilize.

A mother's height has a highly significant impact on the nutritional status of the child. The effect has been interpreted in the past as representing unobserved family background characteristics in addition to capturing genetic influences and the mother's health endowment (Horton, 1986; Barrera, 1990; Thomas, Strauss, and Henriques, 1990). Moreover, the mother is recognized to have an environmental effect on child nutritional status through the womb.

In all of the models, mother's education has a positive and significant effect on children's nutritional status. And it is only secondary and post secondary education of the mother that matter. Education often helps mothers to understand how to deal with nutrition, disease, and sanitation most effectively. In addition, education influences other socioeconomic characteristics like the age at which women marry, the number of children

\footnotetext{
${ }^{8}$ In estimating the response of child nutritional status here, the mortality rate faced by each family is treated as predetermined as we are using average regional rates. In doing so we undoubtedly neglect some feedback effect from malnutrition to mortality.
} 
they have, and their status within the community. The fact that a father has completed primary education, on the other side, seems to be related with worse nutritional status of the children. The same unexpected finding has been reported in previous studies of determinants of child nutritional outcome in developing countries (Skoufias, 1998).

We observe no significant effect of a mother's age, in line with previous analysis of child malnutrition in Peru (Ruggeri Laderchi, 2001).

Indigenous children are significantly more malnourished than non-indigenous children. There are a number of characteristics that may contribute to lower indigenous children's height relative to non-indigenous children, such as the fact that they tend to live in lowincome households, in rural areas and have less-educated parents. After controlling for income and other household and individual characteristics, ethnicity is still an important determinant of child growth attainment; but note that the effect of ethnicity diminishes significantly $(-32 \%)$ once we take into account for differences in altitude level ${ }^{9}$ suggesting that ethnicity captures many unobserved geographical and community characteristics.

Household resource availability has a substantial and significant effect on children nutritional status in Peru. Other household demographic characteristics, like household size, number of children and number of adult women, also appear to be important correlates of child growth. Children living in larger household and household with other preschool children appear to be at disadvantage in terms of growth, suggesting the existence of competition for resources and care. ${ }^{10}$ On the other side, the number of adult women has a positive effect on child nutrition, especially if women are older (the effect of the number of women between 26 and 65 years is more than double than that of women between 16 and 25) suggesting that experience has a relevant effect on nutritional outcome.

Living in rural areas was not related to stunting once other variables were taken into account.

We controlled for two groups of community covariates: the environment children live in and the degree of modernization their families are exposed to. After controlling for altitude and for clustering in the data the only environmental characteristic that seems to matter is the proportion of households in the community with sanitation, which has a substantial positive effect on child's growth. Improved sanitation is expected to be associated with reduced exposure to infectious agents and therefore better health status.

Turning to our measures of community modernization, only the effect of proportion of households with a television is positive and significant and robust to different model

\footnotetext{
${ }^{9}$ The coefficient of ethnicity declines from -0.238 to -0.161 after controlling for altitude.

${ }^{10}$ Note that the inclusion of fertility variables in the model presents an additional problem; fertility, like child health, is part of the household decision making process. Estimates of the effect of fertility on child health are therefore likely to suffer from endogeneity bias. Omitting the fertility variables, on the other side, would introduce bias in the other coefficients. For this reason we decided to include the variables in the model but to be careful in interpreting their effect on child health.
} 
specifications. The result suggests the existence of a positive diffusion process: having a television may influence attitudes and behaviors related to childcare and nutrition in the community. Moreover, the higher prevalence of household with a television in the village may reflect higher socioeconomic status not captured by other community indicators in the models.

At the bottom of table 3 we present the estimates of the random effects at the individual, family and community level, and of the intra-cluster correlation. If we were to take children at random from the whole population, their variance would be the sum of individual, household and community level variance. The intra-family correlation represents the proportion of the total variance due to variation between families (ad since children living in the same family also live in the same community intra family correlation depends both on community and family level random effects) while the intracommunity correlation represents the proportion of the total variance to variation across communities. The intra-family variation remains as large as .236 in model 3 and 4 and .233 in model 5. The result would suggest that, even after taking into account the effect of different covariates, children living in the same families are more similar in their anthropometric outcome than children chosen at random. We therefore gain more accurate estimates and standard errors by fitting a multilevel model.

Table 3 - Results of Multilevel Linear Regression Models

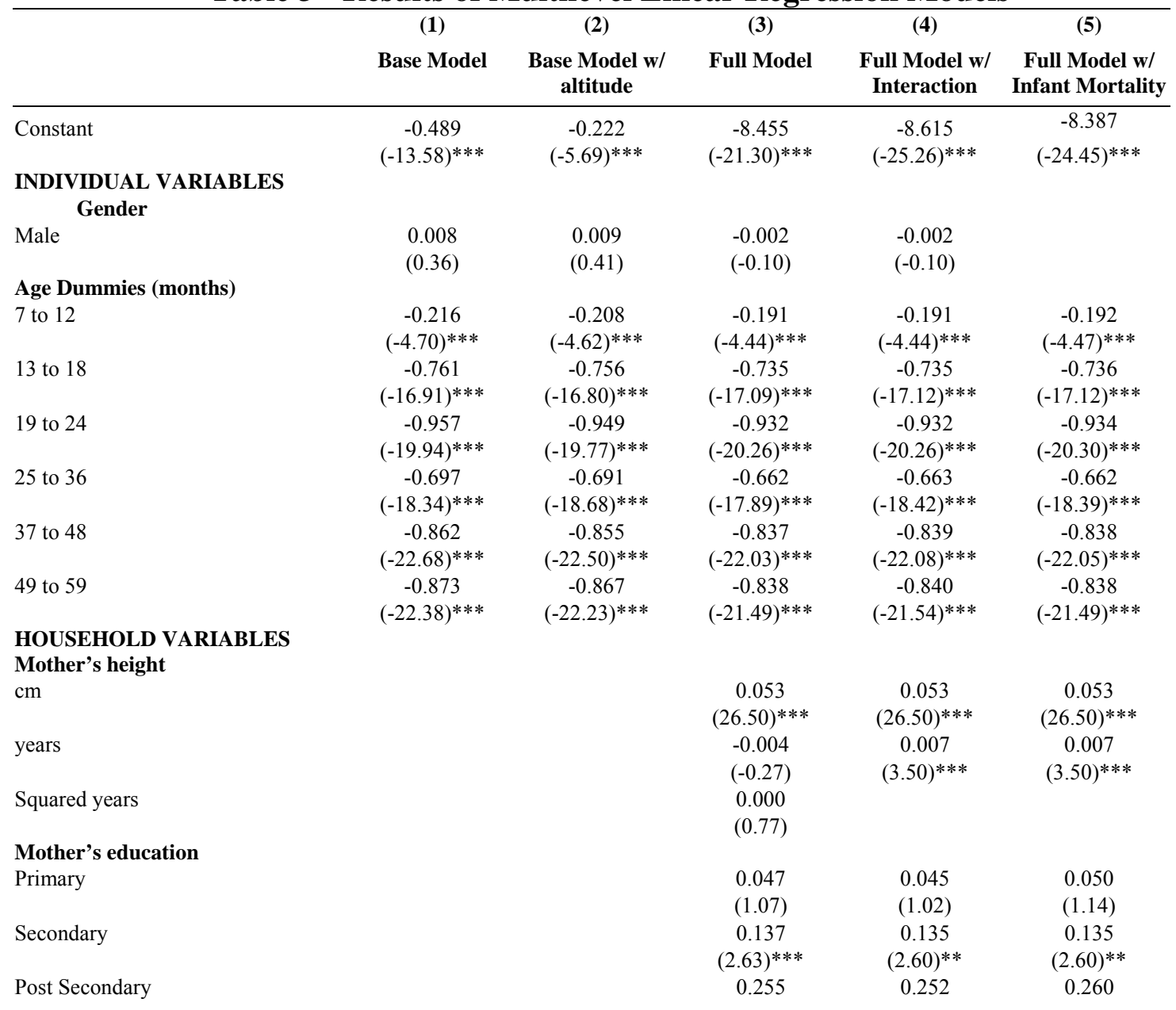


Mother's ethnicity

Indigenous

Father's education

Primary

Secondary

Post Secondary

Household Resources

Asset index

Household Composition

Number of members

Children $<5$

Number of women 16-25

Number of women 26-65

COMMUNITY CHARACTERISTICS

Geographical Characteristics

Altitude 1500-2500 mt

Altitude 2500-3500 mt

Altitude $>=3500 \mathrm{mt}$

Urban area

Public Health Infrastructure

$\%$ hhs with floor of dirt

$\%$ hhs with water piped into house

$\%$ hhs with water from river/stream

$\%$ hhs with flush toilet in the house

$\%$ hhs without toilet

$\%$ hhs with electricity access

Modernization

$\%$ hhs with tv

$\%$ hhs with fridge

$\%$ hhs with tel - fixed or mobile

\section{Migration}

Moved before child's birth

Migration interacted w/ altitude

1500-2500

Migration interacted w/ altitude 2500-3500

Migration interacted w/ altitude >

3500

Public Health

Infant Mortality Rate

Observations

$\begin{array}{ccc}(4.05)^{* * *} & (4.00)^{* * *} & (4.13)^{* * *} \\ -0.161 & -0.163 & -0.133 \\ (-4.24)^{* * *} & (-4.29)^{* * *} & (-3.50)^{* * *} \\ & & \\ -0.102 & -0.105 & -0.096 \\ (-2.22)^{* *} & (-2.28)^{* *} & (-2.09)^{* *} \\ -0.010 & -0.014 & -0.008 \\ (-0.22) & (-0.31) & (-0.18) \\ -0.006 & -0.008 & 0.005 \\ (-0.11) & (-0.15) & (0.09) \\ & & \\ 0.152 & 0.150 & 0.150 \\ (5.24)^{* * *} & (5.17)^{* * *} & (5.17)^{* * *} \\ & & \\ -0.060 & -0.060 & -0.058 \\ (-8.57)^{* * *} & (-8.57)^{* * *} & (-8.29)^{* * *} \\ -0.093 & -0.096 & -0.098 \\ (-4.43)^{* * *} & (-4.57)^{* * *} & (-4.67)^{* * *} \\ 0.053 & 0.059 & 0.060 \\ (2.41)^{* *} & (2.81)^{* * *} & (2.86)^{* * *} \\ 0.132 & 0.129 & 0.126 \\ (5.28)^{* * *} & (5.16)^{* * *} & (5.04)^{* * *}\end{array}$

$-0.276$

$(-4.12)^{* * *}$

$-0.682$

$(-14.21)^{* * *}$

$-0.806$

$(-14.93)^{* * *}$

$-0.108$

$(-2.20)^{* *}$

$-0.287$

$(-7.00)^{* * *}$

$-0.265$

$(-5.89)^{* * *}$

$-0.048$

$(-1.09)$

$-0.013$

$(-0.25)$

$-0.054$

$(-0.95)$

0.091

(1.60)

0.176

$(2.67)^{* * * *}$

$-0.006$

$(-0.11)$

$-0.009$

$(-0.14)$

0.289

$(4.01)^{* * *}$

0.105

(1.31)

0.152

(1.65)

$-0.026$

$(-0.42)$

$-0.308$

$(-6.16)^{* * *}$

$-0.257$

$(-4.43)^{* * *}$

$-0.049$

(-1.11)

$-0.008$

$(-0.15)$

$-0.052$

$(-0.91)$

0.094

(1.65)

0.176

$(2.67)^{* * *}$

$-0.006$

$(-0.11)$

$-0.005$

(-0.08)

0.288

$(4.00)^{* * *}$

0.104

(1.30)

0.151

(1.64)

0.070

$(2.41)^{* *}$

0.082

$(2.28)^{* * *}$

$-0.18$

$(-2.14)^{* *}$

0.03

$(0.54)$

$-0.02$

$(-0.30)$

$-0.005$

$(-5.00)^{* * *}$

11508 


\begin{tabular}{|c|c|c|c|c|c|}
\hline \multicolumn{6}{|l|}{$R$-squared } \\
\hline$-2 *$ LL & 37,376 & 37,069 & 35,793 & 35,168 & 35,149 \\
\hline \multicolumn{6}{|c|}{ RANDOM EFFECTS } \\
\hline$\sigma_{c}^{2}+\sigma_{f}^{2}+\sigma_{i}^{2}$ & 1.696 & 1.580 & 1.271 & 1.269 & 1.266 \\
\hline$\sigma_{c}^{2}$ & 0.372 & 0.258 & 0.056 & 0.056 & 0.052 \\
\hline$\sigma_{\mathrm{f}}^{2}$ & 0.342 & 0.341 & 0.244 & 0.243 & 0.243 \\
\hline$\sigma_{i}^{2}$ & 0.982 & 0.981 & 0.971 & 0.97 & 0.971 \\
\hline \multicolumn{6}{|c|}{ VARIANCE DECOMPOSITION (\% TOTAL) } \\
\hline Community level & 21.9 & 16.3 & 4.4 & 4.4 & 4.1 \\
\hline Household level & 20.2 & 21.6 & 19.2 & 19.1 & 19.2 \\
\hline Individual level & 57.9 & 62.1 & 76.4 & 76.4 & 76.7 \\
\hline \multicolumn{6}{|c|}{ INTRA CLUSTER CORRELATION } \\
\hline$\rho_{\mathrm{c}}$ & 0.219 & 0.163 & 0.044 & 0.044 & 0.041 \\
\hline$\rho_{f}$ & 0.421 & 0.379 & 0.236 & 0.236 & 0.233 \\
\hline
\end{tabular}

\section{CONCLUSIONS}

In this application we explore the relationship between the nutritional status of Peruvian children and the altitude of the communities where they live. Previous studies examined the same relationship mainly from a biological perspective and were unable to control for the effect of different confounding factors. We investigate the relationship between altitude and child health within the classic microeconomic model of the household and use multilevel models to control for clustering and to be able, at the same time, to incorporate altitude into the model. The study shows that anthropometric outcomes of children in the same community are more homogeneous than observations chosen at random, thus violating the assumption of independent observations that underlies classical statistical analysis. The first main implication of the study is that by employing multilevel models we gain more accurate estimates. The second important result is that the effect of altitude on child nutritional status is highly significant, suggesting robustness of the relationship. Moreover, after controlling for the individual, household and community characteristics, the relationship between altitude and child nutritional status becomes non-linear. Peruvian children living at medium/high altitudes (between 2500 and 3500 meters) appear to be worse off than children living at extremely high altitudes (above 3500 meters). The large proportion of community level variance explained by the model (85\%) suggests that most of the variables explaining differences between various communities have been included, although some caution should be used as the altitude variables could be capturing other geographical and environmental characteristics not included in our model. Third, the study suggests that altitude affects nutritional status of the child independently of the duration of the exposure and therefore hypoxia may not be the driving mechanism. The process of adjustment and adaptation to a new community and its social life, on the other side, can have a negative effect on the nutritional outcome of the child. 


\section{References}

Alderman, H., J. Hentschel and R. Sabates, With the Help of One's Neighbors: Externalities in the Production of Nutrition in Peru, ), Social Science and Medicine, forthcoming.

Angeles, G., D.K. Guilkey, T.A. Mroz, The Impact of Community Level Variables on Individual Level Outcomes: Theoretical Results and Demographic Applications, MEASURE Evaluation Working Paper Series No. 50, April 2002

Baker, 1969, Human Adaptation at High Altitude, Science, 163, 1149-1156.

Barrera, A., 1990. "The Role of Maternal Schooling and Its Interactions with Public Health Programs in Child Health Production" Journal of Development Economics, 32.

Beall, C.M., P.T. Baker and J.D. Haas, 1977, The Effects of High Altitude on Adolescent Growth in Southern Peruvian Amerindians, Human Biology Vol. 49(2), pp.109124.

Behrman, J.R. and A.B. Deolalikar. 1988, Health and Nutrition, Chapter 14 in Handbook of Development Economics, Volume I, eds. H. Chenery and T.N. Srinivasan. Amsterdam: Elsever Science Publishers.

Clegg E.J., Pawson I.G., Ashton E.H., Finn R.M., The growth of Children at Different Altitudes in Ethiopia, Philos Trans Soc Land, 264, pp. 403-437.

Cotlear, D., 1986, Technological and institutional change among the Peruvian peasantry: a comparison of three regions at different levels of agricultural development, $\mathrm{PhD}$ Thesis, Oxford University.

Frisancho A.R. and P.T. Baker, 1970, Altitude and Growth: a Study of the Patterns of Physical Growth of a High-altitude Peruvian Quechua Population, American Journal of Physical Anthropology, 32:179-292.

Frisancho, A.R., G.A. Borkan and J.E. Klayman, 1975, Pattern of Growth of Lowland and Highland Peruvian Quechua of Similar Genetic Composition, Human Biology, Vol. 47, pp. 233-243.

Goldstein, H. 1995, Multilevel Statistical Models, Second Edition, Arnold, London.

Gordon, A.S., F.J. Zornetta, d'Angelo and H.A. Charipper, 1943, Effects Of Low Atmospheric Pressure On The Activity Of The Thyroid, Reproductive System And Anterior Lob Of The Pituitary In The Rat, Endocrinology, 33, 366-383.

Gragnolati, M., 1999, "Child Malnutrition in Rural Guatemala: A Multilevel Statistical Analysis" PhD Dissertation. Office of Population Research, Princeton University. 
Greksa, LP, 1986, Growth Patterns of Europeans and Amerindian High-Altitude Natives, Current Anthropology, 27 (1): 72-74.

Haas, J. 1976, Prenatal and Infant Growth and Development, pp. 161-179 in Man in the Andes, Multidisciplinary Study of High Altitude Quechua, eds. P.T. Baker and M.A. Little, Stroudsburg, PA: Dowden, Hutchinson and Ross.

Hoff, 1974, Altitudinal Variations in the Physical Growth and Development of Peruvian Quechua, Homo, 24: 87-99.

Horton, S, 1988, "Birth Order and Child Nutritional Status: Evidence from the Philippines" Economic Development and Cultural Change, January: 341-45.

Hox and Kreft, 1994, Multilevel Analysis Methods, Sociological Methods and Research, Vol. 22 (3): 283-299.

Keller W. 1983. "Choice of Indicators of Nutritional Status" in Evaluation of Nutrition Education in Third World Communities, Ed. B. Schurch. Nestle' Foundation Publication Series. Bern: Hans Huber Publishers.

Kreft, I. And J. de Leeuw, 1994, Multiple Regression Analysis, Sociological Methods and Research, Vol. 22 (3): 319-341.

Kreft, I. And J. de Leeuw, 1998, Introducing Multilevel Modeling, Sage Publications, London.

Leonard, WR, TL Leatherman, JW Carey, RB Thomas, 1990, Contributions of Nutrition Versus Hypoxia to Growth in Rural Andean Populations, American Journal of Human Biology, 2: 613-626.

Martorell, R. and N.S. Scrimshaw, 1995, The Effects of Improved Nutrition in Early Childhood: the Institute of Nutrition of Central America and Panama (INCAP) Follow-up Study, Journal of Nutrition, 125 (4S), pp.1027S-1138S.

Moore, C. and D. Price, 1948, A Study At High Altitude Of Reproduction, Growth, Sexual Maturity And Organ Weights, J. Exp. Zool., 108, 171-216.

Mosley, W.H. and L. Chen. 1984, An Analytical Framework for the Study of Child Survival in Developing Countries, pp. 25-48 in Child Survival: Strategies for Research, eds. W.H. Mosley and L.C. Chen. Supplement to Population and Development Review 10.

Mueller, W.H., V.N. Schull, W.J. Schull, P. Soto, F. Rothhammer, A Multinational Andean genetic and Health Program: Growth and Development in an Hypoxic Environment, Annals of Human Biology, 5(4): 329-352.

Pawson, I.G., 1977, Growth characteristics of populations of Tibetan origin in Nepal, American Journal of Physical Anthropology, Vol. 47(3), pp. 473-82. 
Rasbash J., W. Browne,H. Goldstein, M. Yang, I. Plewis, M. Healy, G. Woodhouse, D. Draper, I. Langford and T. Lewis, 2000, A User's Guide to MLwiN, Centre for Multilevel Modeling, Institute of Education, University of London.

Rasbash, J., M. Yang, G. Woodhouse, and H. Goldstein. 1995. Mln: Command Reference Guide: London: Institute of Education.

Ruggeri Laderchi, C., 2001, Killing Two Birds with One Stone? The Effectiveness Of Food Transfers On Nutrition And Monetary Poverty, QEHWPS74, Oxford.

Skoufias, E., 1998. "Determinants of Child Health During the Economic Transition in Romania”, Word Development, Vol. 26, No. 11, pp. 2045-2056.

Strauss, J. and D. Thomas, 1998, Health, Nutrition and Economic Development, Journal of Economic Literature, Vol. XXXVI, pp.766-817.

Thomas, D., J. Strauss, M.-H. Henriques. 1990. "Child Survival, Height for Age and Household Characteristics in Brazil" Journal of Development Economics 33:197234. 